\title{
Effects of intraseptal infusion of muscimol on inhibitory avoidance and spatial learning: Differential effects of pretraining and posttraining administration
}

\author{
ALAN H. NAGAHARA, JORGE D. BRIONI, and JAMES L. MCGAUGH \\ University of California, Irvine, California
}

\begin{abstract}
Previous research in our laboratory showed that the pretraining administration of the GABAergic agonist muscimol into the medial septal area (MSA) of rats impaired place learning in a watermaze task. To determine whether this treatment impaired memory by acting at the time of training or after training, the first experiment examined the effects of posttraining intraseptal infusion of muscimol on retention in the place-learning task. The posttraining muscimol treatment facilitated learning on the second day of training ( 1 and $5 \mathrm{nmol}$ ) and produced an impairment on only one of the three retention measures on the free-swim trial $(5 \mathrm{nmol})$. In additional experiments using an inhibitory avoidance task, pretraining, but not posttraining, administration of muscimol ( $5 \mathrm{nmol}$ ) into the MSA impaired retention. The findings of these experiments suggest that intraseptal administration of muscimol impairs memory formation primarily by affecting processes occurring at the time of training.
\end{abstract}

Considerable evidence indicates that the septohippocampal system plays an important role in learning and memory in rodents. Lesions of the medial septal area (MSA) or the connection between the MSA and hippocampus produce memory impairments similar to those observed with hippocampus lesions (e.g., Gray \& McNaughton, 1983; Kesner, Crutcher, \& Beers, 1989; Olton, 1990). Numerous studies examining the effects of disruption of the cholinergic system in the hippocampus (Blozovski, 1979; Blozovski \& Hennocq, 1982; Chrobak, Hanin, \& Walsh, 1987; Tateishi et al., 1987), as well as studies examining the correlation between hippocampal cholinergic activity and retention performance (Decker, Pelleymounter, \& Gallagher, 1988; Galey, Toumane, Durkin, \& Jaffard, 1989; Gallagher \& Pelleymounter, 1988; Glick, Mittag, \& Green, 1973; Symons, Davis, \& Marriott, 1988), have implicated the cholinergic septohippocampal system in memory. However, other components of the septohippocampal projection (e.g., GABAergic) are probably also involved in influencing memory.

Several studies have examined the role of the septohippocampal system in memory by examining the effects of

This research was supported by USPHS Grant MH12526 from NIMH and NIDA, and ONR Contract N00014-J-1626. We thank Lynnette Gamboa and Cindy Bae for technical assistance, Ines IntroiniCollison for comments on a preliminary draft, and Nancy Collett for assistance in the preparation of the manuscript. A. H. Nagahara, J. D. Brioni, and J. L. McGaugh are associated with the Center for the Neurobiology of Learning and Memory at the University of California; A. H. Nagahara and J. L. McGaugh are also associated with the Department of Psychobiology. Correspondence should be addressed to A. H. Nagahara, Center for the Neurobiology of Learning and Memory, University of California, Irvine, CA 92717. infusion of GABAergic drugs into the MSA (Brioni, Decker, Gamboa, Izquierdo, \& McGaugh, 1990, Chrobak, Stackman, \& Walsh, 1989; Givens \& Olton, 1990). The septohippocampal neurons are regulated, in part, by a GABAergic projection from the lateral septal nucleus. Anatomical studies indicate that GABAergic neurons in the lateral septal nucleus project to the area of the MSA containing both the septohippocampal cholinergic and GABAergic neurons (Leranth \& Frotscher, 1989; Onteniente, Tago, Kimura, \& Maeda, 1986). In addition, infusion of GABAergic agonists into the MSA inhibits cholinergic activity in the hippocampus as measured by high-affinity choline uptake (HACU) and acetylcholine turnover rate (Brioni et al., 1990; Wood, 1986; Wood, Cheney, \& Costa, 1979). Infusion of the GABAergic agonist muscimol into the MSA also blocks theta activity in the hippocampus (Allen \& Crawford, 1984; Miura, Ito, \& Kadokawa, 1987). Injections of muscimol into the MSA have been reported to impair rats' performance on a delayed radial-arm maze task, an alternation task, and the Morris water-maze task (Brioni et al., 1990, Chrobak et al., 1989; Givens \& Olton, 1990).

In our laboratory, we reported that, in rats, pretraining injections of the GABA agonist muscimol into the MSA impair the acquisition of a place-learning task in the Morris water maze (Brioni et al., 1990). Although these findings demonstrate that infusion of muscimol into the MSA prior to training impairs retention performance in a spatial learning task, it is not clear whether the effects were due to influences on memory processes occurring during training or after training (i.e., consolidation). We have observed that posttraining infusion of muscimol into the amygdala impairs retention of an inhibitory avoid- 
ance task, suggesting a disruption of the consolidation of memory (Brioni et al., 1990). To examine further the role of the septohippocampal system in memory, the present experiments investigated the effect of posttraining injections of muscimol into the MSA on retention in the Morris water-maze task, as well as the effects of pretraining and posttraining intraseptal injections of muscimol on retention in an inhibitory avoidance task.

\section{GENERAL METHODS}

\section{Subjects}

Male Sprague-Dawley rats (60 days old, $200-250 \mathrm{~g}$ on arrival) from Charles River Laboratories were used. The animals were individually housed and maintained on a 12-h light:dark cycle (lights on at 7:00 a.m.), with food and water available ab lib. The animals were acclimatized to laboratory conditions for 1 week before undergoing surgery.

\section{Surgical Procedures}

The animals were implanted with a cannula aimed at the MSA region, using stereotaxic surgical procedures. They were anesthetized with sodium pentobarbital $(50 \mathrm{mg} / \mathrm{kg}, \mathrm{i} . \mathrm{p}$.) and were given atropine sulfate $(0.4 \mathrm{mg} / \mathrm{kg}$, i.p.). The cannulae were constructed of 23-ga stainless steel tubing (I.D. 0.305 mm, O.D. $0.635 \mathrm{~mm}$ ) and were $15 \mathrm{~mm}$ in length. The tip of the cannula was implanted immediately dorsal to the MSA region using the following stereotaxic coordinates: A.P. $+0.5 \mathrm{~mm}$ from bregma; M.L. $0.0 \mathrm{~mm}$; D.V. $-4.0 \mathrm{~mm}$ from dura; the nose bar was $-3.3 \mathrm{~mm}$ from the interaural lines (Paxinos \& Watson, 1986). The cannula was fixed to the skull using two screws and dental acrylic. A stylet was inserted in the cannula and retained there at all times except during the injections. Immediately after surgery, the animals received an intramuscular injection of penicillin $(30,000$ units) and were maintained in an incubator until recovery from anesthesia.

\section{Intraseptal (MSA) Injection Procedures}

The animals received intraseptal injections of buffer, 1-nmol muscimol, or 5-nmol muscimol (Sigma) dissolved in phosphate buffer solution immediately after training. The 1- and 5-nmol doses of muscimol were selected on the basis of results of previous experiments demonstrating that these doses had both behavioral and pharmacological effects on HACU in the hippocampus (Brioni et al., 1990). The drugs were infused through a 30-ga injection needle connected with a $10-\mu l$ Hamilton syringe by polyethylene tubing. The injection needle, which was inserted into the guide cannula, protruded $2 \mathrm{~mm}$ beyond the tip of the cannula. The drug was delivered in a volume of $0.5 \mu \mathrm{l}$ over a $37-\mathrm{sec}$ period, using a syringe pump. The injection needle was retained in the guide cannula for an additional $30 \mathrm{sec}$ after the injection before removal.

\section{Histology}

After completion of all behavioral testing, the animals were anesthetized and perfused intracardially with saline and $10 \%$ formalin. The brains were removed and placed in 10\% formalin for at least 1 week. They were then sectioned at $40 \mu \mathrm{m}$ on a freezing microtome and stained with cresyl violet. The animals with improper cannula placements or unusual brain lesions were not included in the statistical analyses.

\section{EXPERIMENT 1}

Experiment 1 examined the effect of posttraining infusion of muscimol into the MSA on acquisition of a water- maze place-learning task. As discussed above, previous evidence (Brioni et al., 1990) indicates that pretraining injections of muscimol into the MSA impair spatial learning of a place-learning task in the Morris water maze. The impaired performance observed in that study might reflect either the disruption of processes occurring during training or the disruption of memory-storage processes occurring after the training. To clarify the basis of the effect, the present experiment examined the effect of posttraining injections of muscimol into the MSA on subsequent retention performance in this task.

\section{Method}

The apparatus was a circular, galvanized steel tank, measuring $1.83 \mathrm{~m}$ in diameter and $0.58 \mathrm{~m}$ in height and filled to a depth of $0.20 \mathrm{~m}$ with $25^{\circ} \mathrm{C}$ water. A $1.70-\mathrm{m}$ white strip extending $0.16 \mathrm{~m}$ from the top was attached to the rim of the tank to serve as a visual salient cue. Other visual cues (c.g., wall poster, cabinets, experimenter) were present in the environment surrounding the tank. A submerged $12 \times 14 \mathrm{~cm}$ Plexiglas platform was located $1 \mathrm{~cm}$ below the water surface in the center of one of the four quadrants of the tank. Rats previously trained in the inhibitory avoidance task (see below) were used in the present experiment. The training procedures used were the same as those that had been used in a previous experiment examining the effect of pretraining injection of muscimol into the MSA on place learning (Brioni et al., 1990). Briefly, on each of the 4 training days, each animal received three training trials from three different starting positions located at the midpoint of each quadrant, except the target quadrant containing the platform. The rat was allowed to swim until it located and climbed onto the submerged platform. If the rat failed to locate the platform within $90 \mathrm{sec}$, it was guided to the platform. The rat remained on the platform for $30 \mathrm{sec}$ before being removed. The intertrial interval was $15 \mathrm{sec}$. Immediately after the third training trial, the animals received intraseptal injections of buffer or muscimol (1- or 5-nmol) solutions as described above. On the 5 th day, the animals were given a 60-sec free-swim trial in the water tank, with the platform removed. The free-swim trial was recorded on videotape and was subsequently analyzed to determine the number of crossings of a $12 \times 14 \mathrm{~cm}$ region located in the center of each quadrant, the latency to cross the target platform position, and the time spent in the target quadrant. The three measures were used to assess the degree of spatial bias of the rats toward the target region during the free swim.

\section{Results}

Figure 1 shows the mean escape latencies on the 4 training days for the buffer $(n=10), 1-\mathrm{nmol}(n=9)$, and 5 -nmol $(n=8)$ groups. As the intraseptal injections were administered posttraining, the results on Day 1 reflect behavior prior to the first drug administration. There were no significant differences among the groups on Day 1 . Therefore, statistical analyses were performed on the results from Days 2-4. As shown in Figure 1, the mean escape latencies decreased over days $[F(2,46)=15.86$, $p<.001]$. In addition, there was a significant drug effect $[F(2,46)=4.42, p<.05]$, as well as a significant drug $\times$ day interaction $[F(4,46)=3.23, p<.05]$. Subsequent analyses of the individual training days revealed that, on Day 2, the escape latencies of both the 1-nmol muscimol group $[t(17)=5.35, p<.05]$ and the $5-\mathrm{nmol}$ 


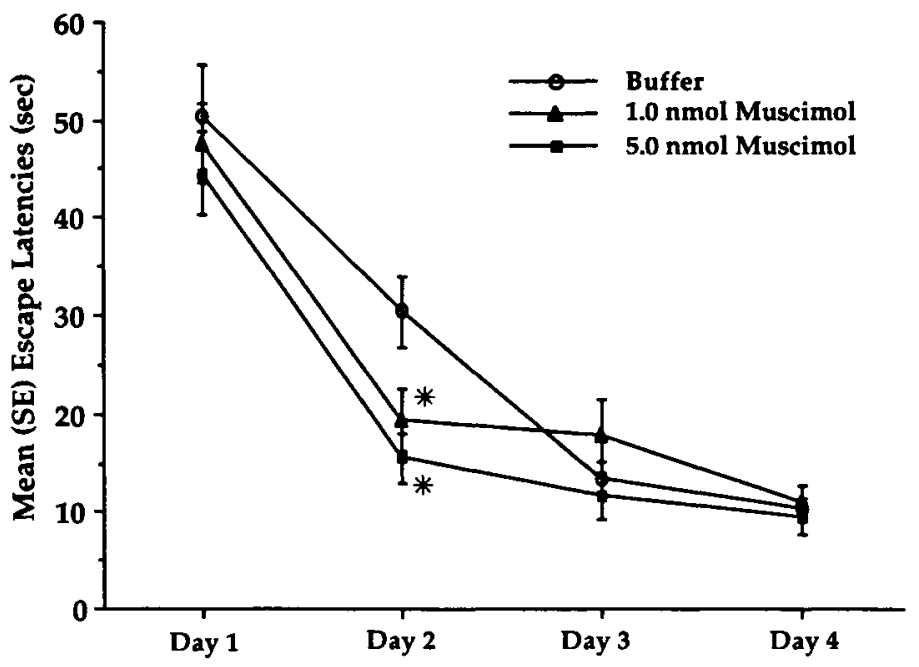

Figure 1. Effects of posttraining intraseptal infusion of muscimol on mean escape latencies in the place-learning task in the water maze. The escape latencies of the 1-nmol $(n=9)$ and 5-nmol $(n=8)$ muscimol groups were significantly lower than those of the buffer group $(n=10)$ on the second day of training. ${ }^{*} p<.05$ versus buffer group.

muscimol group $[t(16)=10.47, p<.01]$ were significantly lower than those of the buffer group. Table 1 shows the results of the three measures recorded on the freeswim trial. A significant difference was observed on the measure of time spent in the target quadrant $[F(2,22)=$ $5.50, p<.05]$. Subsequent analysis revealed that the time in the target quadrant of the 5-nmol-muscimol-treated animals was significantly lower than that of the buffer-treated animals $[t(14)=12.12, p<.01]$. However, no drug effect was observed on either the latency to cross the target region $[F(2,22)=0.86, p>.40]$ or the number of crossings of the target region $[F(2,22)=2.44, p>.10]$.

\section{Discussion}

The results of Experiment 1 suggest that posttraining intraseptal injections of muscimol facilitated the initial learning of the place-learning task, as indicated by the escape latencies on Day 2, the day following the first posttraining injection. However, no significant differences were observed on Days 3 and 4 . In contrast, in the previous study from our laboratory (Brioni et al., 1990), and subsequent experiments (Nagahara, 1990), pretraining in-

Table 1

The Effects of Intraseptal Administration of Muscimol During Place Learning on Three Measures of Retention on the Free-Swim Trial

\begin{tabular}{|c|c|c|c|c|c|c|}
\hline \multirow[b]{2}{*}{ Groups } & \multicolumn{2}{|c|}{$\begin{array}{l}\text { Target Quadrant } \\
\text { Time (sec) } \\
\end{array}$} & \multicolumn{2}{|c|}{$\begin{array}{c}\text { Crossing } \\
\text { Latency }(\mathrm{sec})\end{array}$} & \multicolumn{2}{|c|}{$\begin{array}{c}\text { Target } \\
\text { Crossings }\end{array}$} \\
\hline & $M$ & $S E$ & $M$ & $S E$ & $M$ & $S E$ \\
\hline Buffer & 24.39 & 1.47 & 10.90 & 3.30 & 3.90 & .55 \\
\hline 1-nmol Muscimol & 24.86 & 2.29 & 10.56 & 3.41 & 4.56 & .92 \\
\hline 5-nmol Muscimol & 17.95 & 1.95 & 18.67 & 7.84 & 3.33 & 1.02 \\
\hline
\end{tabular}

traseptal injections of muscimol significantly impaired performance on the training trials. Thus, the present findings suggest that it is unlikely that the impairing effects induced by pretraining injections of muscimol into the MSA are due to the disruption of memory-storage processes occurring after training. On the free-swim retention test the 5-nmol muscimol group, but not the 1-nmol muscimol group, showed retention impairment, as measured by the time in the target quadrant during the free swim. However, the two muscimol groups did not differ from the controls in the other two free-swim measures. In contrast, previous findings from our laboratory indicated that pretraining injections of 1- or 5-nmol muscimol significantly impair retention, as indexed by all three measures recorded on the free-swim trial. Such findings indicate that the memory-impairing effects of pretraining injections of muscimol are greater than those produced by posttraining injections. Considered together, these results support the view that the effects of pretraining injections of muscimol on performance in this task are due primarily to influences on memory processes occurring at the time of acquisition rather than to actions on posttraining processes underlying memory consolidation.

\section{EXPERIMENT 2}

Experiment 2 tested the effect of pretraining and posttraining intraseptal injection of muscimol on retention in an inhibitory avoidance task. The findings of Experiment 1 , considered together with previous findings, suggest a differential effect of pretraining and posttraining injection of muscimol into MSA on memory. To determine the generality of this effect, Experiment 2 examined the effects of intraseptal injections of muscimol ad- 
ministered either before or after training in a one-trial inhibitory avoidance task.

\section{Method}

The animals were trained on a trough-shaped avoidance apparatus consisting of two compartments separated by a sliding door (Liang et al., 1982). The starting compartment was illuminated by a tensor lamp ( $25 \mathrm{~W})$. On the training day, the rat was placed in the starting compartment with its head facing away from the door. When the rat turned around, the door leading to the dark compartment was opened and the timer was started. When the rat entered the dark compartment, the door was closed, a low footshock $(0.5 \mathrm{~mA}, 1.0 \mathrm{sec})$ was administered through the metal floor plates of the compartment and the rat's latency to enter the compartment was recorded. On the retention test $48 \mathrm{~h}$ later, the rat was placed into the starting compartment and the latency to enter the dark compartment (maximum of $600 \mathrm{sec}$ ) was recorded. Different groups of animals received an intraseptal injection of either muscimol (1 or $5 \mathrm{nmol}$ ) or buffer $5 \mathrm{~min}$ prior to training or immediately after training, according to the procedures described above.

\section{Results}

The retention performance of the three groups given posttraining intraseptal injections is shown in Figure 2. Although retention latencies of both muscimol groups were higher than those of the control group, no significant group differences were observed $[H(2,28)=1.05$, $p>$.50]. Figure 3 shows the retention performance of the three groups given pretraining intraseptal injections. Statistical analysis showed a significant difference between the three groups $[H(2,29)=6.16, p<.05]$. Subsequent analyses showed that the retention latencies of the 5-nmol muscimol group were significantly lower than those of the buffer group $[U(9,10)=17, p<.05]$. The retention latencies of the 1-nmol muscimol group did not differ significantly from those of the buffer group $[U(9,10)=$
$30.5, p<.20]$ or from those of the 5 -nmol muscimol group $[U(9,9)=35.5, p>.5]$.

\section{Discussion}

The findings of Experiment 2 indicate that pretraining intraseptal injections of 5-nmol muscimol significantly impaired retention in the inhibitory avoidance task. In contrast, posttraining injections did not significantly affect retention. The absence of a posttraining effect indicates that the effects of pretraining injections of muscimol on memory are not due to effects on processes occurring after training. Furthermore, since intraseptal injections of muscimol do not affect footshock thresholds (Nagahara, 1990), the effects of pretraining injections cannot be attributed to a decreased sensitivity to the footshock administered during the training. The findings of this experiment are comparable to those observed in experiments examining the effects of intraseptal injections of muscimol on place learning in the Morris water maze (Brioni et al., 1990, and the present Experiment 1) and, thus, provide additional evidence suggesting that intraseptal injections of muscimol impair memory processes occurring at the time of acquisition, but not memory processes occurring following acquisition (i.e., consolidation) in these two tasks.

\section{GENERAL DISCUSSION}

The findings of the present set of experiments, considered together with the results of other experiments from our laboratory (Brioni et al., 1990; Nagahara, 1990), indicate that pretraining intraseptal injections of muscimol significantly impair retention of the inhibitory avoidance task, as well as the Morris water-maze task. In contrast,

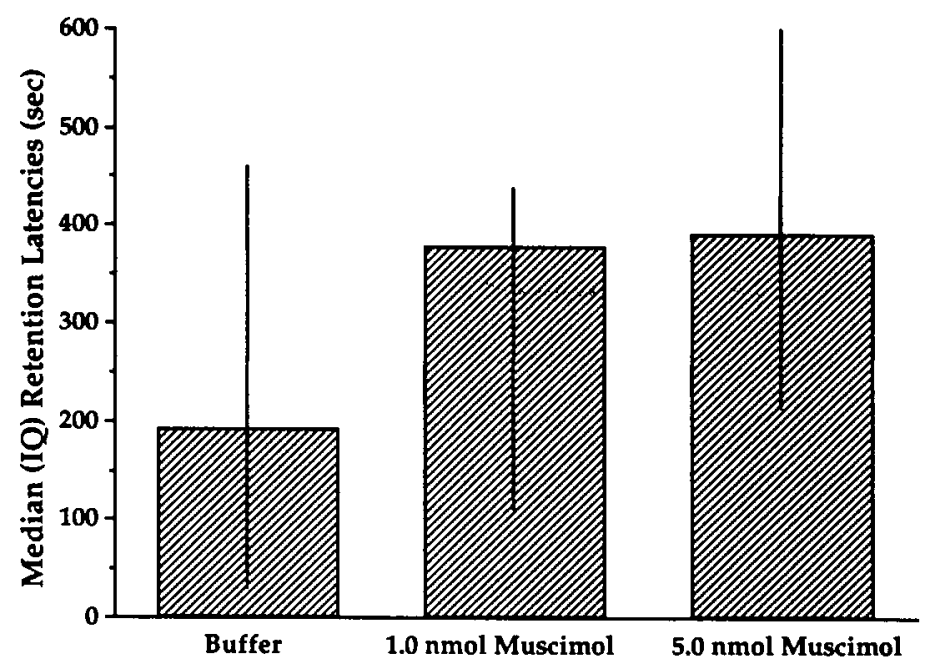

Figure 2. Effects of posttraining intraseptal infusion of muscimol on retention latencies in the inhibitory avoidance task. The retention latencies of the 1 -nmol $(n=9)$ and 5-nmol $(n=8)$ muscimol groups did not differ significantly from those of the buffer group $(n=10)$. 


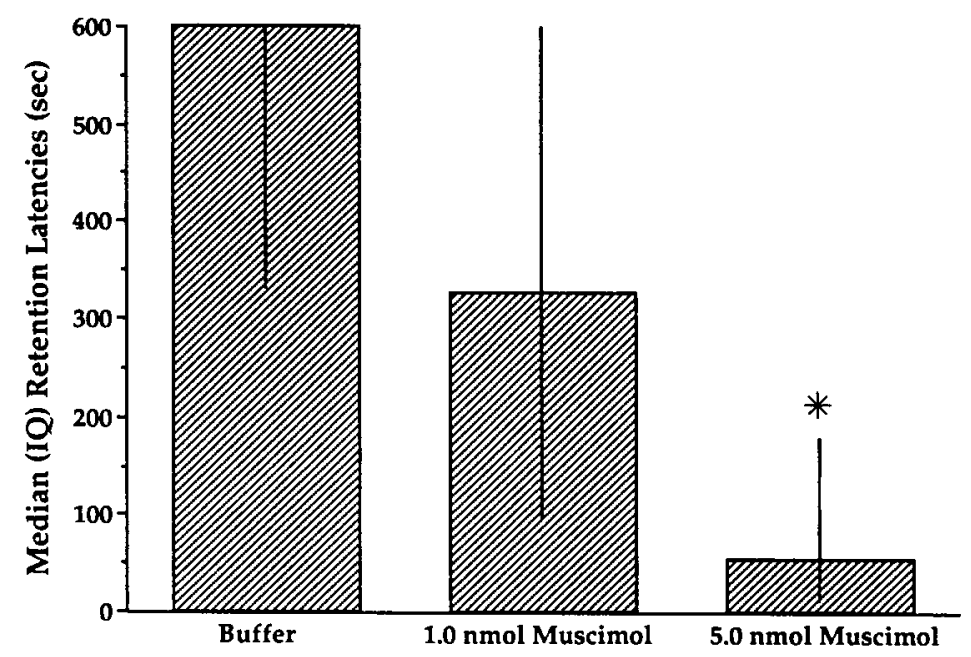

\begin{abstract}
Figure 3. Effects of pretraining intraseptal administration of muscimol on retention latencies in the inhibitory avoidance task. The retention latencies of the 5-nmol group $(n=9)$ were significantly lower than those of the buffer group $(n=10)$. The retention latencies of the 1-nmol group $(n=9)$ did not differ significantly from those of the buffer controls. ${ }^{*} p<.05$ versus buffer group.
\end{abstract}

posttraining intraseptal injections of muscimol failed to produce consistent impairment of retention in either of these two tasks. The results of these experiments thus suggest that the memory-impairing effects of intraseptal injections of muscimol administered prior to training are due to influences on processes occurring at the time of training, rather than after training. Mizumori, Perez, Alvarado, Barnes, and McNaughton (1990) reported obtaining similar results in experiments examining the effects of intraseptal injections of the local anesthetic tetracaine: Pretraining, but not posttraining, injections of tetracaine into the MSA impaired 4-h retention on a radial-arm maze task.

As noted above, several lines of evidence suggest that a GABAergic projection from the lateral septal nucleus directly synapses onto and inhibits the septohippocampal cholinergic projection neurons (Bassant, Jobert, Dutar, \& Lamour, 1988; Brioni et al., 1990; Leranth \& Frotscher, 1989; Wood, 1986). Various manipulations that disrupt the septohippocampal cholinergic system generally result in impaired memory retention (e.g., Blozovski, 1979; Blozovski \& Hennocq, 1982; Chrobak et al., 1987; Tateishi et al., 1987). Thus, the present findings that intraseptal infusion of muscimol impaired memory on two tasks may well reflect an inhibition of the septohippocampal cholinergic system. However, the action of the intraseptal infusion of muscimol on memory may be mediated, in part, by an action on noncholinergic septohippocampal projection neurons located in the same area (Freund, 1989; Freund \& Antal, 1988; Onteniente et al., 1986; Panula, Revuelta, Cheney, Wu, \& Costa, 1984).

The memory-impairing effects of treatments administered before training are, of course, difficult to interpret. The effect of pretraining intraseptal injections of muscimol on memory may reflect a direct action on memory processes. Or, alternatively, they may reflect disruption of sensory, motor, or motivational processes. However, in other recent experiments, we found that pretraining intraseptal injections of muscimol impaired retention in the inhibitory avoidance and place-learning tasks only after a delay between training and testing (Nagahara \& McGaugh, in press). That is, there was no impairment of retention tested immediately after training. Thus, this evidence indicates that MSA injections of muscimol do not affect sensory, motor, motivational, or shortterm memory processes essential for the acquisition and performance of these two tasks.

There is, however, other evidence suggesting that posttraining manipulations of the MSA can affect retention. Posttraining electrical stimulation of the MSA has been reported to affect retention in a variety of tasks (Galey et al., 1989; Landfield, 1977; Wetzel, Ott, \& Matthies, 1977). Furthermore, the findings of Experiment 1 indicated that posttraining MSA injections of muscimol facilitated the initial acquisition (i.e., Trial 2 performance) of the place-learning task. Findings of other investigators (Chrobak et al., 1989; Chrobak \& Napier, 1990) indicate that posttraining injections of either a GABAergic agonist or a GABAergic antagonist can impair memory in a radialarm maze task; however, the differential effects of pretraining and posttraining treatments were not examined in those experiments. The basis of the difference in the effects of posttraining MSA treatments on retention of the tasks used in these experiments and our experiments remains to be determined.

In contrast to our findings indicating a lack of consistent effects of posttraining intraseptal injections on memory, many studies have shown that posttraining systemic 
injections of GABAergic drugs affect memory in a variety of tasks (e.g., Bovet, McGaugh, \& Oliverio, 1966; Breen \& McGaugh, 1961; Brioni \& McGaugh, 1988; Castellano, Brioni, Nagahara, \& McGaugh, 1989; McGaugh, Castellano, \& Brioni, 1990). In addition, we have previously observed that posttraining injection of GABAergic agonists injected into the amygdaloid complex of rats impairs retention in an inhibitory avoidance task (Brioni et al., 1990; Castellano et al., 1989). Posttraining injections of muscimol into the nucleus basalis magnocellularis also impair memory retention of an inhibitory avoidance task (Nagel \& Huston, 1988). These results suggest that GABAergic systems in different brain regions are differentially involved in the acquisition and consolidation of memory.

Posttraining injections of muscimol into the MSA significantly enhanced the initial acquisition of the placelearning task and slightly, but insignificantly, increased the retention latencies in inhibitory avoidance task. Although these effects are, at best, modest, they may reflect a slight retrograde enhancement of retention similar to that observed with benzodiazepines. This is of particular interest as the effects of benzodiazepines, like those of GABAergic drugs, are mediated by the GABAergic receptor complex. Findings of studies using human subjects (e.g., Berenberg, Dorow, Duka, \& Sauerbrey, 1988; Ghoneim, Hinrichs, \& Mewaldt, 1984; Hinrichs, Ghoneim, \& Mewaldt, 1984; Ott, Rohloff, Aufdembrinke, \& Fichte, 1988) as well as rats (Cahill, Brioni, \& Izquierdo, $1986)$ indicate that systemically administered benzodiazepines produce retrograde enhancement of retention of information acquired immediately before drug administration. Furthermore, in human subjects as well as rats, benzodiazepines generally produce memory impairment when administered before training, but not when administered after training (Cahill et al., 1986; Jensen, Martinez, Vasquez, \& McGaugh, 1979; Hinrichs et al., 1984). Thus, the retention-modulating effects of MSA injections of muscimol are similar to those induced by systemically administered benzodiazepines. Also, as with intraseptal administration of muscimol, both systemic and intraseptal injections of benzodiazepines decrease hippocampal cholinergic activity and theta rhythm (Bassant et al., 1988; Brunello \& Cheney, 1981; Miller \& Richter, 1985; Richter, Gormley, Holtman, \& Simon, 1982; Stackman, Emerich, Taylor, \& Walsh, 1989). Such evidence suggests that the retention-influencing effects of systemically administered benzodiazepines and intraseptally administered muscimol on memory may be mediated by common influences.

\section{REFERENCES}

Allen, C. A., Crawford, I. L. (1984). GABAergic agents in the medial septal nucleus affect hippocampal theta rhythm and acetylcholine utilization. Brain Research, 322, 261-267.

Bassant, M. H., Jobert, A., Dutar, P., Lamour, Y. (1988). Effect of psychotropic drugs on identified septohippocampal neurons. Neuroscience, 27, 911-920.
Berenberg, D., Dorow, R., Duka, T., Sauerbrey, N. (1988). Benzodiazepine receptor ligands: Tools for memory research clinical pharmacology. Psychopharmacology Series, 6, 261-274.

BLozovskı, D. (1979). PA-Learning in young rats with dorsal hippocampal- and hippocampo-entorhinal atropine. Pharmacology Biochemistry \& Behavior, 10, 369-372.

Blozovski, D., HeNnoce, N. (1982). Effects of antimuscarinic cholinergic drugs injected systemically or into the hippocampoentorhinal area upon passive avoidance learning in young rats. Psychopharmacology, 76, 351-358.

Bovet, D., McGAugh, J. L., \& OLiverjo, A. (1966). Effects of posttrial administration of drugs on avoidance learning on mice. Life Science, 5, 1309-1315.

Breen, R. A., McGaugh, J. L. (1961). Facilitation of maze learning with posttrial injections of picrotoxin. Joumal of Comparative Physiology \& Psychology, 54, 498-501.

Brioni, J. D., Decker, M. W., Gamboa, L. P., Izquierdo, I., . McGaugh, J. L. (1990). Muscimol injections in the medial septum impair spatial learning. Brain Research, 522, 227-234.

Brioni, J. D., MCGAUGH, J. L. (1988). Post-training administration of GABAergic antagonists enhances retention of aversively motivated tasks. Psychopharmacology, 96, 505-510.

Brunello, N., a Cheney, D. L. (1981). The septal-hippocampal cholinergic pathway: Role in antagonism of pentobarbital anesthesia and regulation by various afferents. Journal of Pharmacology \& Experimental Therapeutics, 219, 489-495.

Cahill, L., Brioni, J., \& IzQuierdo, I. (1986). Retrograde memory enhancement by diazepam: Its relation to anterograde amnesia, and some clinical implications. Psychopharmacology, 90, 554-556.

Castellano, C., Broni, J. D., Nagahara, A. H., McGaugh, J. L. (1989). Post-training systemic and intra-amygdala administration of the GABA-B agonist baclofen impairs retention. Behavioral \& $\mathrm{Neu}$ ral Biology, 52, 170-179.

Chrobak, J. J., Hanin, I., Walsh, T. J. (1987). AF64A (ethylcholine aziridinium ion), a cholinergic neurotoxin, selectively impairs working memory in a multiple component $\mathrm{T}$-maze task. Brain $\mathrm{Re}$ search, 414, 15-21.

Chrobak, J. J., NAPier, T. C. (1990). Intraseptal administration of bicuculline produces memory deficits in the rat. Society for Neuroscience Abstracts, 16, 136.

Chrobak, J. J., Stackman, R. W., W Walsh, T. J. (1989). Intraseptal administration of muscimol produces dose-dependent memory impairments in the rat. Behavioral \& Neural Biology, 52, 357-369.

Decker, M. W., Pelleymounter, M. A., a Gallagher, M. (1988). Effects of training on a spatial memory task on high affinity choline uptake in hippocampus and cortex in young adult and aged rats. Joumal of Neuroscience, 8, 90-99.

FREUND, T. F. (1989). GABAergic septohippocampal neurons contain parvalbumin. Brain Research, 478, 375-381.

FREUND, T. F., ANTAL, M. (1988). GABA-containing neurons in the septum control inhibitory interneurons in the hippocampus. $\mathrm{Na}$ ture, 336, 170-173.

Galey, D., Toumane, A., Durkin, T., J Jafard, R. (1989). In vivo modulation of septo-hippocampal cholinergic activity in mice: Relationships with spatial reference and working memory performance. Behavioural Brain Research, 32, 163-172.

Gallagher, M., Pelleymounter, M. A. (1988). An age-related spatial learning deficit: Choline uptake distinguishes "impaired" and "unimpaired" rats. Neurobiology of Aging, 9, 363-369.

Ghoneim, M. M., Hinrichs, J. V., MEWALDT, S. P. (1984). Doseresponse analysis of the behavioral effects of diazepam: I. Learning and memory. Psychopharmacology, 82, 291-295.

Givens, B. S., Olton, D. S. (1990). Cholinergic and GABAergic modulation of medial septal area: Effects on working memory. Behavioral Neuroscience, 104, 849-855.

Guck, S. D., Mrttag, T. W., \& GreEN, J. P. (1973). Central cholinergic correlates of impaired leaming. Neuropharmacology, 12, 291-296.

Gray, J. A., McNaughton, N. (1983). Comparison between the behavioural effects of septal and hippocampal lesions: A review. Neuroscience \& Biobehavioral Reviews, 7, 119-188.

Hinrichs, J. V., Ghoneim, M. M., Mewaldt, S. P. (1984). Di- 
azepam and memory: Retrograde facilitation produced by interference reduction. Psychopharmacology, 84, 158-162.

Jensen, R. A., Martinez, J. L., Jr., Vasquez, B. J., McGaugh, J. L. (1979). Benzodiazepines alter acquisition and retention of an inhibitory avoidance response in mice. Psychopharmacology, 64, 125-126.

Kesner, R. P., Crutcher, K., \& Beers, D. R. (1989). Serial position curves for item (spatial location) information: Role of the dorsal hippocampus and medial septum. Brain Research, 454, 219-226.

LANDFIELD, P. W. (1977). Different effects of post-trial driving or blocking of the theta rhythm on avoidance learning in rats. Physiology \& Behavior, 18, 439-445.

Leranth, C., \& Frotscher, M. (1989). Organization of the septal region in the rat brain: Cholinergic-GABAergic interconnections and the termination of hippocampal-septal fibers. Journal of Comparative Neurology, 289, 304-314.

Liang, K. C., McGaugh, J. L., Martinez, J. L., Jr., Jensen, R. A., VAsquez, J., Messing, R. B. (1982). Post-training amygdaloid lesions impair retention of an inhibitory avoidance response. Behavioural Brain Research, 4, 237-249.

McGaugh, J. L., Castellano, C., Brioni, J. (1990). Picrotoxin enhances latent extinction of conditioned fear. Behavioral Neuroscience, 104, 262-265.

Miller, J. A., Richter, J. A. (1985). Effects of anticonvulsants in vivo on high affinity choline uptake in vitro in mouse hippocampal synaptosomes. British Journal of Pharmacology, 84, 19-25.

MiURA, Y., Ito, T., Kadokawa, T. (1987). Effects of intraseptally injected dopamine and noradrenaline on hippocampal synchronized theta wave activity in rats. Japanese Journal of Pharmacology, 44, 471-479.

Mizumori, S. Y. J., Perez, G. M., Alvarado, M. C., Barnes, C. A., \& McNaughton, B. L. (1990). Reversible inactivation of medial septum differentially affects two forms of learning in rats. Brain Research, $528,12-20$.

NAGAHARA, A. H. (1990). GABAergic modulation of the medial septal area: Effects on learning and memory. Unpublished doctoral dissertation, University of California, Irvine.

NAGAhARA, A. H., \& MCGAUGH, J. L. (in press). Intraseptal administration of muscimol differentially affects memory at various retention delays. Brain Research

NAGEL, J. A., Huston, J. P. (1988). Enhanced inhibitory avoidance learning produced by post-trial injections of substance $p$ into the basal forebrain. Behavioral \& Neural Biology, 49, 374-385.

OLton, D. S. (1990). Dementia: Animal models of the cognitive impairments following damage to the basal forebrain cholinergic system. Brain Research Bulletin, 25, 499-502.

Onteniente, B., TAgo, H., Kimura, H., \& Maeda, T. (1986). Dis- tribution of gamma-aminobutyric acid-immunoreactive neurons in the septal region of the rat brain. Journal of Comparative Neurology, 248, 422-430.

Ott, H., Rohloff, A., Aufdembrinke, B., Fichte, K. (1988). Anterograde and retrograde amnesia after lormetazepam and flunitrazepam. Psychopharmacology Series, 6, 180-193.

Panula, P., Revuelta, A. V., Cheney, D. L., Wu, J. Y., \& COSTA, E. (1984). An immunohistochemical study on the location of GABAergic neurons in rat septum. Journal of Comparative Neurology, 222, 69-80.

Paxinos, G., \& Watson, C. (1986). The rat brain in stereotaxic coordinates. New York: Academic Press.

Richter, J. A., Gormley, J. M., Holtman, J. R., JR., \& Simon, J. R. (1982). High-affinity choline uptake in the hippocampus: Its relationship to the physiological state produced by administration of barbiturates and other treatments. Journal of Neurochemistry, 39, 1440-1445.

Stackman, R. W., Emerich, D. F., Taylor, L. A., Walsh, T. J. (1989). Intraseptal administration of GABA and benzodiazepine agonists and antagonists: Alteration in hippocampal choline uptake and cognitive behavior. Society for Neuroscience Abstracts, 15, 669.

Symons, J. P., DAvis, R. E., MARriott, J. G. (1988). Water-maze learning and effects of cholinergic drugs in mouse strains with high and low hippocampal pyramidal cell counts. Life Sciences, 42 375-383.

TATeishi, M., Takano, Y., Honda, K., Yamada, K., KamiYa, Y., \& KAMIYA, H. (1987). Effects of intrahippocampal injections of the cholinergic effects of the cholinergic neurotoxin AF64A on presynaptic cholinergic markers and on passive avoidance response in the rat Clinical \& Experimental Pharmacology \& Physiology, 14, 611-618.

Wetzel, W., Ott, T., Matthies, H. (1977). Post-training hippocampal rhythmic slow activity ("theta") elicited by septal stimulation improves memory consolidation in rats. Behavioral Biology, 21, $32-40$.

WoOD, P. L. (1986). Pharmacological evaluation of GABAergic and glutamatergic inputs to the nucleus basalis-cortical and the septalhippocampal cholinergic projections. Canadian Joumal of Physiology \& Pharmacology, 64, 325-328.

Wood, P. L., Cheney, D. L., Costa, E. (1979). An investigation of whether septal gamma-aminobutyrate-containing interneurons are involved in the reduction in the turnover rate of acetylcholine elicited by substance $\mathbf{P}$ and $\mathrm{B}$-endorphin in the hippocampus. Neuroscience, 4, 1479-1484.

(Manuscript received August 26, 1991; revision accepted for publication March 11, 1992.) 